\title{
Preparation and Adsorption Properties of Chitosan-Modified Magnetic Nanoparticles for Removal of Mo (VI) Ions
}

\author{
Lei Chao ${ }^{1}$, Yao Wang ${ }^{1}$, Su Chen ${ }^{2 *}$, Yafeng $\mathrm{Li}^{1}$ \\ ${ }^{1}$ School of Municipal and Environmental Engineering, Shenyang Jianzhu University, Shenyang 110168, China \\ ${ }^{2}$ Key Laboratory of Regional Environment and Eco-Remediation, Shenyang University, Shenyang 110044, China
}

Received: 7 August 2020

Accepted: 3 November 2020

\begin{abstract}
In this study, the new magnetic nanoparticles modified with chitosan were prepared by reverse suspension cross-linking method to solve the problem of excess molybdenum in mining wastewater. The materials were employed for the adsorption of Mo (VI) from water. By adjusting the $\mathrm{pH}$ value of the water sample, the adsorption process of molybdenum was completed after oscillating the adsorbed molybdenum for a period of time between composite nanometer adsorbent and Mo (VI) at a certain speed. The concentration of molybdenum was determined by thiocyanate spectrophotometry. The result showed that under the condition of $\mathrm{pH}=4.0$, the adsorption effect of Mo (VI) on chitosanmodified magnetic nanoparticles was the best. The adsorption process accorded with the Langmuir adsorption isotherm model, and the high fitting degree with the quasi-second-order adsorption kinetic model accorded with chemical adsorption. Theoretical maximum adsorption capacity was $35.54 \mathrm{mg} / \mathrm{g}$. The adsorption of Mo (VI) on chitosan-modified magnetic nanoparticles was still over $90 \%$ after 3 regenerations. Removal of Mo (VI) by chitosan-modified magnetic nanoparticles is quick and efficient. Its reusability is good. Its magnetic property is strong and it is convenient for solid-liquid magnetic separation. More importantly, our results provide a sustainable approach for removal of Mo (VI), chitosan-modified magnetic nanoparticles have more potential to be exploited and utilized for metal adsorption.
\end{abstract}

Keywords: molybdenum, magnetic nanoparticles, chitosan, adsorption, water treatment

\section{Introduction}

Molybdenum is a necessary trace element for both plants and animals and is also an important resource. Nowadays, molybdenum is widely used in China's

*e-mail:mailchensu@aliyun.com semiconductor and optoelectronic industries because of its high melting point, high temperature resistance, good corrosion resistance and good thermal conductivity [1]. In addition, molybdenum is found in corrosion inhibitors, fertilizers and alloys [2]. Lianshan District of Huludao City is an important molybdenum industry base in China, accounting for one-third of the country's molybdenum resources. Many molybdenum industry 
enterprises in mining wastewater discharge treatment is not up to standard, after simple precipitation treatment directly into the water body, resulting in a serious molybdenum content exceeding the standard. As the exploration of molybdenum mines increases, the molybdenum pollution problem is becoming even more serious. Moreover, molybdenum pollution has been reported worldwide, such as in Erdenet Mine, Mongolia [3]; Wujintang Reservoir, China [4]; Modonkul River, Russian [5]; and Dabaoshan Mine, China [6]. For adults and older children, the recommended daily intake of molybdenum is 75-250 $\mathrm{g}$ [7]. The pollution of molybdenum to natural water environment will lead to the accumulation of molybdenum in food chain and cause chronic poisoning, so it is very important to remove heavy metal molybdenum from water environment. Excessive molybdenum intake can lead to adverse effects such as anemia, growth retardation, kidney stones and urethral calculi [7]. However, according to the effluent data of the mining wastewater from a molybdenum mining enterprise in Liaoning Province, the Mo (VI) concentration can reach about $20 \mathrm{mg} / \mathrm{L}$. The World Health Organization (WHO) recommend the stheindicator for molybdenum in drinking water is $0.07 \mathrm{mg} / \mathrm{L}$, the lack of feasible methods for Mo removal from aqueous solutions has become a growing concern for the sustainable use of natural resources [8].

Currently, many methods, e.g., chemical precipitation, ion-exchange and adsorption have been developed for Mo (VI) pollution control in aqueous solutions, and most of them have been demonstrated to be effective under certain environmental conditions [9-11]. Adsorption is now considered as an efficient and rapid way to remove heavy metals from water. Many researchers have investigated low-cost, biodegradable substitutes made from natural resources to remove toxic ions from wastewater [12-13]. Therefore, developing a low-cost and environmentally-friendly adsorbent with higher adsorption capacity is of importance and urgency [14]. Nanomaterials are widely used in the adsorption of organic dyes and heavy metals in water environment because of their small particle size, large surface area and high adsorbability [15-19]. Finding a nanoadsorbent that can quickly and effectively remove Mo (VI) in aqueous environment is a key issue. Chitosan is a natural polymer material, and a large number of active groups such as amino and hydroxyl groups exist on chitosan, which not only has good adsorption performance, but also has the characteristics of low cost and biodegradability [20]. Through the researches of Budnyak et al. [21], Brion-Roby et al. [22], Bertoni et al. [23], chitosan has strong adsorption on Mo (VI). The adsorption effect is good, at the same time, there is still a difficult problem of solid-liquid separation. Magnetic nanoparticles are easily magnetic separation and highly reusable adsorption materials. A large number of literatures have focused on the studies of magnetic nano-adsorption materials removing heavy metals such as $\mathrm{Cd}, \mathrm{Cu}, \mathrm{Sb}, \mathrm{Cr}$ [24- 27], while there are few studies on $\mathrm{Mo}$. $\mathrm{Fe}_{3} \mathrm{O}_{4}$ is widely used in magnetic nanomaterials, so that the composite adsorption materials not only have high adsorption characteristics of nanoparticles, but also are endowed with magnetism. Hence, we consider coating chitosan with good adsorption performance on the $\mathrm{Fe}_{3} \mathrm{O}_{4}$ surface to form a composite adsorption material which is easy to magnetic separation.

Since there is no report on the improvement of Mo (VI) adsorption efficiency by chitosan-modified magnetic $\mathrm{Fe}_{3} \mathrm{O}_{4}$ nanoparticles, the adsorption characteristics of $\mathrm{Fe}_{3} \mathrm{O}_{4}$ /CTS magnetic nanoparticles by fitting the adsorption isotherms and adsorption kinetics was studied in this work. The chitosan-modified magnetic nanoparticle was prepared in this paper. The structure, morphology, magnetic properties and surface charge properties were characterized by XRD, IR, SEM and Zeta potential, respectively. In this paper, we determine the experimental conditions for adsorption Mo (VI) of composite adsorption materials and study the adsorption characteristics of $\mathrm{Fe}_{3} \mathrm{O}_{4} / \mathrm{CTS}$ magnetic nanoparticles. Because the adsorption material is endowed with magnetism, the relationship between the regeneration times of the adsorption material and the removal rate of Mo (VI) is tested in this paper to study the adsorption and regeneration ability of $\mathrm{Fe}_{3} \mathrm{O}_{4} / \mathrm{CTS}$ magnetic nanoparticles.

\section{Materials and Methods}

\section{Materials}

All chemical reagents were of analytical grade and the solutions in this study were prepared by deionized water. Chitosan, $\mathrm{Na}_{2} \mathrm{MoO}_{4} \cdot 2 \mathrm{H}_{2} \mathrm{O}$, ascorbic acid were purchased from Shanghai Lanji Technology Development Co., Ltd. $\mathrm{NH}_{4} \mathrm{SCN},\left(\mathrm{NH}_{4}\right)_{2} \mathrm{Fe}\left(\mathrm{SO}_{4}\right)_{2} \cdot 6 \mathrm{H}_{2} \mathrm{O}$, $\mathrm{Fe}\left(\mathrm{SO}_{4}\right)_{2}, \mathrm{NaOH}, \mathrm{NaHCO}_{3}$ were purchased from Tianjin Hengxing Chemical Reagent Co., Ltd. Ethanol anhydrous, $\mathrm{CH}_{3} \mathrm{COOH}$, Paraffin liquid, Petroleum ether were purchased from Tianjin Fuyu Fine Chemical Co., Ltd. Glutaraldehyde, Propanone, $\mathrm{NH}_{3} \cdot \mathrm{H}_{2} \mathrm{O}, \mathrm{H}_{2} \mathrm{O}_{2}$, $\mathrm{H}_{2} \mathrm{SO}_{4}, \mathrm{HCl}$ were purchased from Tianjin Ruijin Special Chemicals Co., Ltd. Span-80 was purchased from Tianjin Damao Chemical Reagent Factory. PEG-20000 was purchased from Tianjin Institute of Guangfu Fine Chemical Industry.

\section{Synthesis of $\mathrm{Fe}_{3} \mathrm{O}_{4} /$ CTS Magnetic Nanoparticles}

Chitosan-modified magnetic nanoparticles were synthesized by $\mathrm{H}_{2} \mathrm{O}_{2}$ oxidation hydrothermal method. Dissolving $0.60 \mathrm{~g}$ of chitosan in $5 \%$ acetic acid, and then $\mathrm{Fe}_{3} \mathrm{O}_{4}$ magnetic nanoparticles were dissolved in chitosan solution by 1:1 mass ratio. Add $40 \mathrm{~mL}$ paraffin liquid, $1.5 \mathrm{~mL}$ Span-80, disperse in the Ultrasonic Cleaner (KQ-100E, China) for $20 \mathrm{~min}$, and add $9 \mathrm{~mL}$ of $25 \%$ glutaraldehyde. After $4 \mathrm{~h}$ mechanical stirring, 
the prepared substances were fully washed by petroleum ether, acetone and deionized water. Dry the resulting solid material in a Circulating Water Vacuum Pump (SHZ-D, Germany) at $60^{\circ} \mathrm{C}$ and grind it fully into a solid powder reserve [28].

\section{Characterization of Magnetic Nanoparticles}

The dry powder-like $\mathrm{Fe}_{3} \mathrm{O}_{4}$ magnetic nanoparticles and the chitosan-modified magnetic nanoparticles were identified by X-ray diffractometer. The scanning angle of the two particles was $10^{\circ}-80^{\circ}$. Within the wavenumber range of $400 \mathrm{~cm}^{-1}$ to $4000 \mathrm{~cm}^{-1}$, three kinds of particles: $\mathrm{Fe}_{3} \mathrm{O}_{4}$ magnetic nanoparticles, chitosan and chitosan-modified magnetic nanoparticle were scanned by infrared spectrometer. The sample was dispersed in ethanol solution and observed by scanning electron microscope under the condition of $5 \mathrm{KV}$. Zeta potential measurements were formed by Malvern Nanosize Potentiometer at different pHs. The magnetic field intensity was measured when the magnetic field was in the range of $-20000 \mathrm{Oe}-20000 \mathrm{Oe}$.

\section{Adsorption and Desorption Studies}

Adsorption test: first, the $\mathrm{pH}$ of raw water was adjusted to 5.0 by $0.1 \mathrm{~mol} / \mathrm{L} \mathrm{HCl}$ and $0.1 \mathrm{~mol} / \mathrm{L} \mathrm{NaOH}$. Weighing $0.40 \mathrm{~g} \mathrm{Fe}_{3} \mathrm{O}_{4} / \mathrm{CTS}$ magnetic nanoparticles and mixing with $100 \mathrm{~mL}$ Mo (VI) wastewater in a conical flask. In the oscillating incubator (HZQ-X100, China), $150 \mathrm{r} / \mathrm{min}$ was used for oscillating adsorption, and then the magnetic separation of solid and liquid was obtained [29]. Mo (VI) concentration was determined by thiocyanate spectrophotometry [30], while adsorption capacity of Mo (VI) by $\mathrm{Fe}_{3} \mathrm{O}_{4} / \mathrm{CTS}$ magnetic nanoparticles was calculated by Eq. (1):

$$
Q_{t}=\frac{\left(C_{0}-C_{t}\right) \times V}{M}
$$

...where $\mathrm{Q}_{\mathrm{t}}(\mathrm{mg} / \mathrm{g})$ was the adsorption capacity at $\mathrm{t}$ moment. $\mathrm{C}_{0}(\mathrm{mg} / \mathrm{L})$ and $\mathrm{C}_{\mathrm{t}}(\mathrm{mg} / \mathrm{L})$ was initial concentration of $\mathrm{Mo}$ (VI) and concentration after adsorption $\mathrm{t}$ time, respectively. $\mathrm{V}(\mathrm{mL})$ was the volume of water containing molybdenum solution, and $\mathrm{M}(\mathrm{g})$ was the adsorbent quality.

Regeneration test: using $\mathrm{Fe}_{3} \mathrm{O}_{4} / \mathrm{CTS}$ magnetic nanoparticles to adsorb Mo (VI) at room temperature. After reaching the adsorption equilibrium, the adsorption material was left in the conical bottle by the method of solid-liquid magnetic separation. Equipped with $0.01 \mathrm{~mol} / \mathrm{L} \mathrm{NaOH}$ solution, $\mathrm{Fe}_{3} \mathrm{O}_{4} / \mathrm{CTS}$ magnetic nanoparticles were ultrasonically desorbed by $20 \mathrm{~mL}$ $\mathrm{NaOH}$ solution for $30 \mathrm{~min}$, then treated with deionized water ultrasonic for $30 \mathrm{~min}$ after magnetic separation. The regenerated magnetic nanoparticles were obtained after solid-liquid magnetic separation. The reusability characteristics of magnetic adsorption materials were investigated. The adsorption tests were carried out at room temperature [31].

\section{Results and Discussion}

\section{Characterization of $\mathrm{Fe}_{3} \mathrm{O}_{4} / \mathrm{CTS}$ Magnetic Nanoparticles}

X-ray diffractometer scans of a) $\mathrm{Fe}_{3} \mathrm{O}_{4}$ and b) $\mathrm{Fe}_{3} \mathrm{O}_{4} / \mathrm{CTS}$ were shown in Fig. 1. In the XRD patterns of the two adsorbed materials, there were six typical diffraction peaks around $30.3^{\circ}, 35.7^{\circ}, 43.3^{\circ}, 53.4^{\circ}, 57.2^{\circ}$ and $62.8^{\circ}$, corresponding to different crystal planes (220), (311), (400), (422), (511) and (440), respectively. Comparing the curve of $\mathrm{Fe}_{3} \mathrm{O}_{4} / \mathrm{CTS}$ (Fig. 1b) with the standard diffraction card $\mathrm{Fe}_{3} \mathrm{O}_{4}$ (Fig. 1a), there were no other crystal peaks, indicating that pure $\mathrm{Fe}_{3} \mathrm{O}_{4}$ magnetic nanoparticles were prepared by $\mathrm{H}_{2} \mathrm{O}_{2}$ oxidation method. Whereas the chitosan-modified magnetic nanoparticles were completely consistent with the diffraction peaks of $\mathrm{Fe}_{3} \mathrm{O}_{4}$ magnetic nanoparticles, indicating that the phase transition of $\mathrm{Fe}_{3} \mathrm{O}_{4}$ nanoparticles was not caused during the binding of chitosan, and the crystal structure did not change [32-34].

FTIR spectra of a) CTS, b) $\mathrm{Fe}_{3} \mathrm{O}_{4}$, and c) $\mathrm{Fe}_{3} \mathrm{O}_{4} / \mathrm{CTS}$ were illustrated in Fig. 2. It was shown that the stretching vibration of active groups such as $-\mathrm{NH}_{2}$ and $-\mathrm{OH}$ exist in the FTIR spectra of CTS (Fig. 2a), so there were characteristic absorption peaks near $3360.9 \mathrm{~cm}^{-1}$ in FTIR spectra. After coordination of $\mathrm{Fe}_{3} \mathrm{O}_{4}$ (Fig. 2b), the characteristic absorption peak of $\mathrm{Fe}_{3} \mathrm{O}_{4} / \mathrm{CTS}$ (Fig. 2c) magnetic nanoparticles was obviously offset, and the absorption peak moved to $3330.9 \mathrm{~cm}^{-1}$ in the direction of low wavenumber. This might be due to the weakening of $\mathrm{N}-\mathrm{H}$ stretching vibration on chitosan after the $\mathrm{Fe}_{3} \mathrm{O}_{4}$ composite, and the formation of $\mathrm{N}-\mathrm{Fe}$ bond enhances. The $\mathrm{C}-\mathrm{H}$ bending

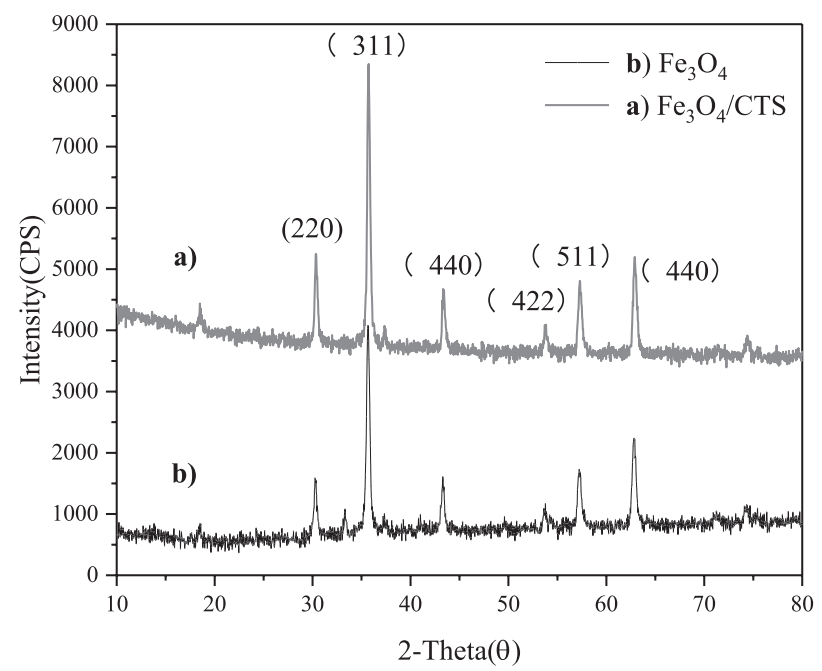

Fig. 1. X-ray diffractometer scans of a) $\mathrm{Fe}_{3} \mathrm{O}_{4}$ and b) $\mathrm{Fe}_{3} \mathrm{O}_{4} / \mathrm{CTS}$. 


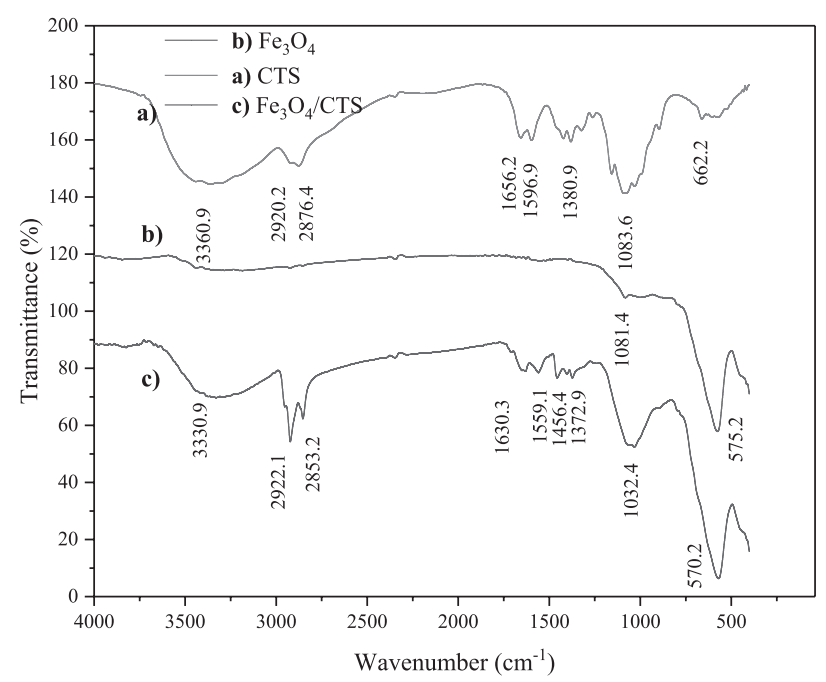

Fig. 2. FTIR spectra of a) CTS, b) $\mathrm{Fe}_{3} \mathrm{O}_{4}$, and c) $\mathrm{Fe}_{3} \mathrm{O}_{4} / \mathrm{CTS}$.

vibration peak at $1380.9 \mathrm{~cm}^{-1}$ also shifted to the low wavenumber due to the formation of composites. In addition, due to the expansion vibration of $\mathrm{C}=\mathrm{N}$, there was a characteristic absorption peak at $1630.3 \mathrm{~cm}^{-1}$, indicating that the crosslinking agent glutaraldehyde had an effect on $\mathrm{NH}_{2}$. Fe-O was the characteristic peak of $\mathrm{Fe}_{3} \mathrm{O}_{4}$, which appeared at $575.2 \mathrm{~cm}^{-1}$ of $\mathrm{Fe}_{3} \mathrm{O}_{4}$ nanoparticles and $570.2 \mathrm{~cm}^{-1}$ of $\mathrm{Fe}_{3} \mathrm{O}_{4} / \mathrm{CTS}$

a)

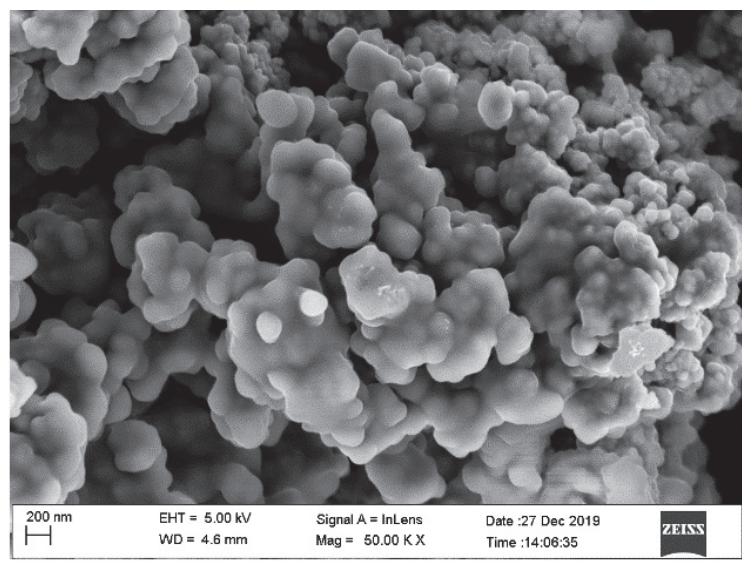

b)

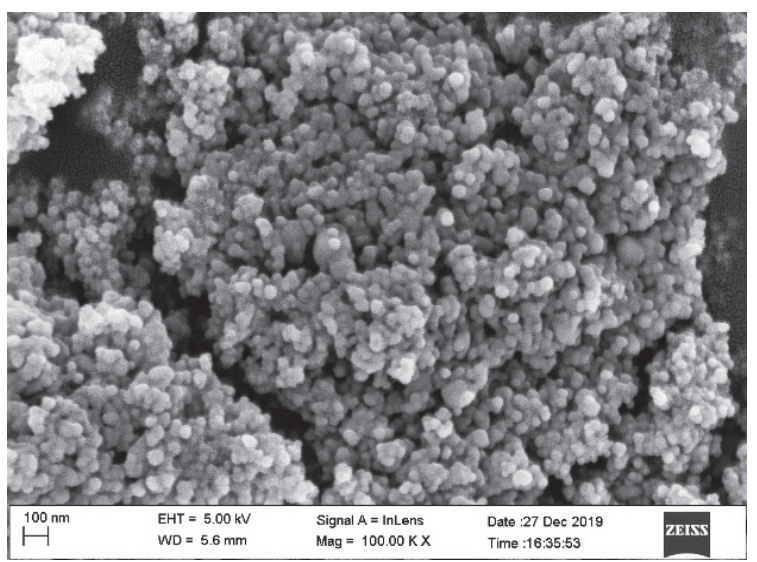

Fig. 3. SEM images of a) $\mathrm{Fe}_{3} \mathrm{O}_{4}$ and b) $\mathrm{Fe}_{3} \mathrm{O}_{4} /$ CTS. nanoparticles, respectively, indicating that $\mathrm{Fe}_{3} \mathrm{O}_{4} / \mathrm{CTS}$ magnetic nanoparticles were formed successfully after the chemical effect of $\mathrm{Fe}_{3} \mathrm{O}_{4}$ on chitosan.

SEM images of a) $\mathrm{Fe}_{3} \mathrm{O}_{4}$ and b) $\mathrm{Fe}_{3} \mathrm{O}_{4} /$ CTS were shown in Fig. 3. Both of them were spherically grained. However, the agglomeration of $\mathrm{Fe}_{3} \mathrm{O}_{4}$ nanoparticles still occurred after encapsulated by CTS. The particles indicated that agglomeration might be formed in the drying process. Because the particle size was very small, the increase of specific surface area led to the increase of active sites on the surface of the particles. The chemical activity increased, that was, chemical stability was poor, which led to the phenomenon of agglomeration.

Fig. 4 showed the hysteresis curves of two magnetic nanoparticles measured at the temperature of $300 \mathrm{~K}$. The saturation magnetization of $\mathrm{Fe}_{3} \mathrm{O}_{4} / \mathrm{CTS}$ magnetic nanoparticles (Fig. 4a) was $51.7 \mathrm{emu} / \mathrm{g}$, which decreased compared with that of $\mathrm{Fe}_{3} \mathrm{O}_{4}$ magnetic nanoparticles (Fig. 4b) with a saturation magnetization of $87.1 \mathrm{emu} / \mathrm{g}$. The reason was that chitosan was successfully coated on the surface of $\mathrm{Fe}_{3} \mathrm{O}_{4}$ particles and weakened its magnetization. It could be seen from the hysteresis curves that the coercivity and remanence of the two magnetic nanomaterials were close to zero, which indicated that both of them had superpara magnetic properties. The magnetic properties of composite nanomaterials could be easily separated from the liquid by external magnetic field after the adsorption reaction was completed. Magnetic composites were easy to recycle and reuse.

The zeta potentials of $\mathrm{Fe}_{3} \mathrm{O}_{4}$ /CTS magnetic nanoparticles under different $\mathrm{pHs}$ were shown in Fig. 5, which determined the surface charge change of the composite when suspended in aqueous medium. Zero potential point $\left(\mathrm{pH}_{\mathrm{pzc}}\right)$ of nanocomposites was observed near $\mathrm{pH}=5.3$. When $\mathrm{pH}<\mathrm{pH}_{\mathrm{pzc}}$, the surface of $\mathrm{Fe}_{3} \mathrm{O}_{4} / \mathrm{CTS}$ nanoparticles was positively charged, and it was easy to adsorb anions by electrostatic

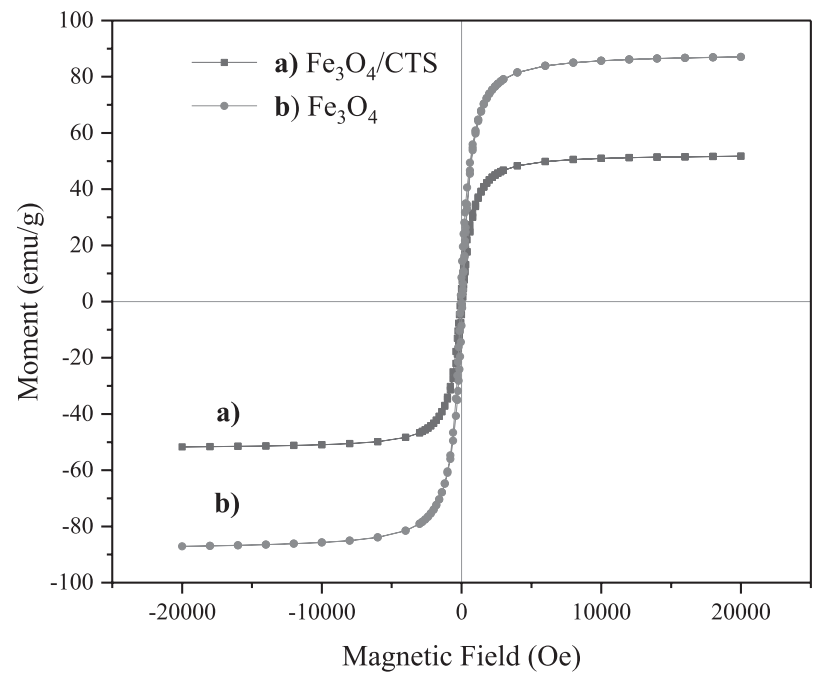

Fig. 4. Hysteresis curves of a) $\mathrm{Fe}_{3} \mathrm{O}_{4}$ and b) $\mathrm{Fe}_{3} \mathrm{O}_{4} / \mathrm{CTS}$. 


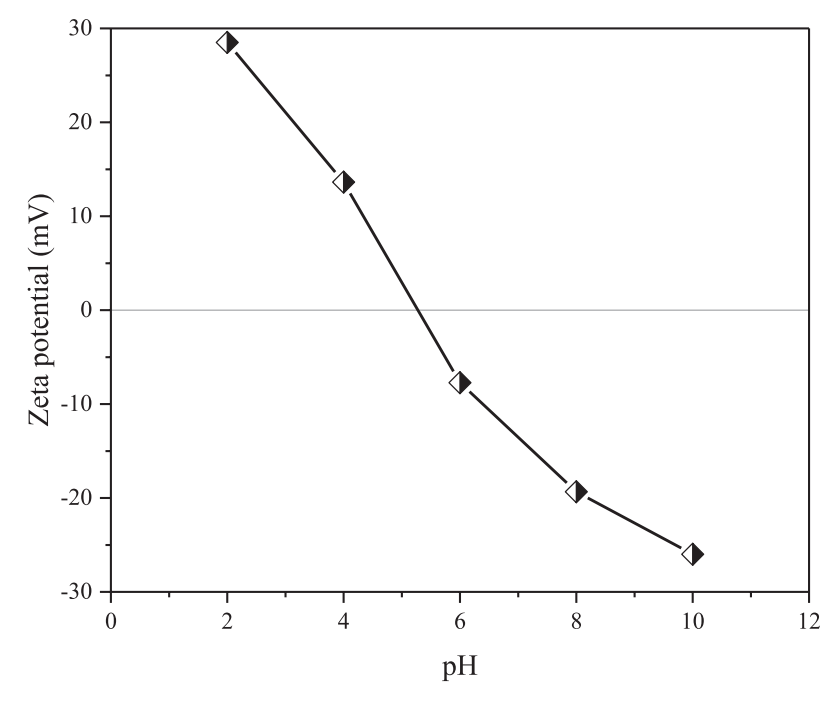

Fig. 5. Zeta potential of $\mathrm{Fe}_{3} \mathrm{O}_{4} / \mathrm{CTS}$.

attraction. However, when $\mathrm{pH}>\mathrm{pH}_{\mathrm{pzc}}$, the surface of the nanoparticles was negatively charged, and the adsorption effect of anion by electrostatic repulsion would be reduced, which tended to adsorb cations [35].

\section{Effect of Initial pH on Adsorption}

The removal of Mo (VI) by nanocomposites under different $\mathrm{pH}$ conditions was studied by adsorption of $0.40 \mathrm{~g} \mathrm{Fe}_{3} \mathrm{O}_{4} / \mathrm{CTS}$ magnetic nanoparticles in the $\mathrm{pH}$ range of 2-10. Removal rates of Mo (VI) under different $\mathrm{pH}$ conditions were shown in Fig. 6. In Fig. 6, the initial $\mathrm{pH}$ of the solution had a great effect on the removal of Mo (VI). The removal rate of Mo (VI) by $\mathrm{Fe}_{3} \mathrm{O}_{4} / \mathrm{CTS}$ magnetic nanoparticles increased first and then decreased with the increase of $\mathrm{pH}$ value. The highest removal rate of Mo (VI) was $94.35 \%$ when the

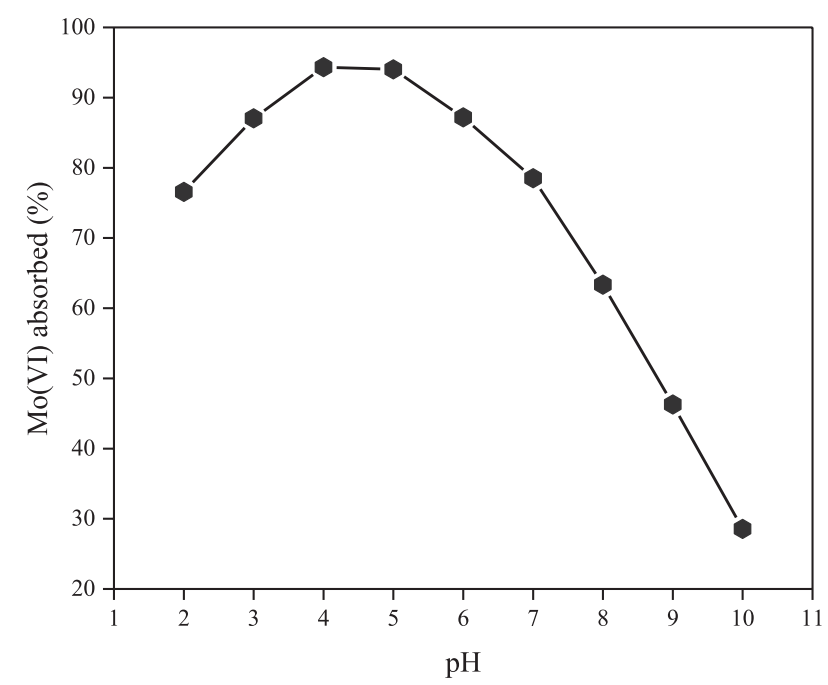

Fig. 6. Removal rates of Mo (VI) under different pHs. Condition: $\mathrm{T}=298 \mathrm{~K}$, solution volume $100 \mathrm{~mL}$, nano-magnetic $\mathrm{Fe}_{3} \mathrm{O}_{4} / \mathrm{CTS}$ $0.40 \mathrm{~g}, 100 \mathrm{~mL}$ of $30 \mathrm{mg} / \mathrm{L} \mathrm{Mo}(\mathrm{VI})$, agitation time of $30 \mathrm{~min}$. initial $\mathrm{pH}$ value was 4 , and the maximum adsorption capacity of magnetic composites was $7.08 \mathrm{mg} / \mathrm{g}$. The presence of Mo (VI) in water and the surface charge of $\mathrm{Fe}_{3} \mathrm{O}_{4} / \mathrm{CTS}$ magnetic nanoparticles were the key factors for the adsorption of Mo (VI) [36]. Guibal et al. [36] studied the presence of molybdenum at concentrations of $10 \mathrm{mg} / \mathrm{L}$ and $100 \mathrm{mg} / \mathrm{L}$ in different $\mathrm{pH}$ values. In neutral to weak acidity, it mainly existed in the form of $\mathrm{MoO}_{4}^{2-}$. The oxygen anions of $\mathrm{HMoO}_{4}^{-}$, $\mathrm{H}_{2} \mathrm{MoO}_{4}, \mathrm{Mo}_{7} \mathrm{O}_{21}(\mathrm{OH})_{3}{ }^{3-}$ and $\mathrm{Mo}_{7} \mathrm{O}_{24}{ }^{6-}$ were also present under acidic conditions. All Mo (VI) except $\mathrm{H}_{2} \mathrm{MoO}_{4}$ were in the form of oxygen anion and $\mathrm{Mo}_{19} \mathrm{O}_{59}{ }^{2-}$ only existed in high concentrations of Mo (VI) solution. Therefore, the concentration of Mo (VI) might also be a factor affecting adsorption efficiency. When initial $\mathrm{pH}$ was less than 4, adsorption of Mo (VI) decreased, probably because a stronger the acidity results in a greater proportion of $\mathrm{H}_{2} \mathrm{MoO}_{4}$. The $\mathrm{pH}$ value did not reach the equipotential point $\left(\mathrm{pH}_{\mathrm{pzc}}\right)$. The surface of $\mathrm{Fe}_{3} \mathrm{O}_{4} /$ CTS magnetic nanoparticles was positively charged, and it easily adsorbed the oxygen anion of molybdenum. The presence of $\mathrm{H}_{2} \mathrm{MoO}_{4}$ might be the main reason for the decrease of Mo (VI) removal rate. Although adsorption efficiency decreased in this range, the removal rate was over $75 \%$. At $\mathrm{pH}=4, \mathrm{H}_{2} \mathrm{MoO}_{4}$ was almost absent from the solution, and its adsorption efficiency was the highest. As the $\mathrm{pH}$ continued to increase, the surface of the $\mathrm{Fe}_{3} \mathrm{O}_{4} / \mathrm{CTS}$ magnetic nanoparticles became even more negatively charged, and the generation of electrostatic repulsion led to a significant decrease in Mo (VI) removal rate.

\section{Adsorption Kinetic Models}

Adsorption kinetics was very important in evaluating the properties of adsorption materials and studying the potential mechanism of the adsorption process [37]. At room temperature, the $\mathrm{pH}$ of molybdenum-containing wastewater was adjusted to $4,100 \mathrm{~mL}$ water sample was added to the conical bottle and $0.04 \mathrm{~g} \mathrm{Fe}_{3} \mathrm{O}_{4} / \mathrm{CTS}$ magnetic nanoparticles were used for oscillating adsorption at $150 \mathrm{r} / \mathrm{min}$ speed until adsorption equilibrium was reached. The adsorption process of $\mathrm{Fe}_{3} \mathrm{O}_{4} / \mathrm{CTS}$ magnetic nanoparticles on Mo (VI) was fitted by pseudo-first-order kinetic equation [38], pseudo-second-order kinetic equation [39] and particle diffusion model respectively, and their equations were expressed as (2)-(4):

$$
\begin{gathered}
\ln \left(Q_{e}-Q_{t}\right)=\ln Q_{e}-\frac{k_{1}}{2.303} t \\
\frac{t}{Q_{t}}=\frac{1}{k_{2} Q_{e}^{2}}+\frac{t}{Q_{e}} \\
Q_{t}=k_{p} t^{1 / 2}+C
\end{gathered}
$$


Table 1. Comparison of the two kinetic models for Mo (VI) adsorption on $\mathrm{Fe}_{3} \mathrm{O}_{4} / \mathrm{CTS}$ magnetic nanoparticles at $298 \mathrm{~K}$.

\begin{tabular}{|c|c|}
\hline Kinetic model & Mo (VI) ion \\
\hline Mo (VI) mass concentration $(\mathrm{mg} / \mathrm{L})$ & 30 \\
\hline $\mathrm{Q}_{\mathrm{e}, \exp }(\mathrm{mg} / \mathrm{g})$ & 7.46 \\
\hline \multicolumn{2}{|l|}{ Pseudo-first-order } \\
\hline $\mathrm{k}_{1}\left(\min ^{-1}\right)$ & 0.036 \\
\hline $\mathrm{Q}_{\mathrm{e}}(\mathrm{mg} / \mathrm{g})$ & 0.803 \\
\hline $\mathrm{R}^{2}$ & 0.7319 \\
\hline \multicolumn{2}{|l|}{ Pseudo-second-order } \\
\hline $\mathrm{k}_{2}(\mathrm{~g} /(\mathrm{mg} \cdot \mathrm{min}))$ & 0.064 \\
\hline $\mathrm{Q}_{\mathrm{e}}(\mathrm{mg} / \mathrm{g})$ & 7.47 \\
\hline $\mathrm{R}^{2}$ & 0.9999 \\
\hline \multicolumn{2}{|l|}{ Internal diffusion model } \\
\hline $\mathrm{k}_{\mathrm{i}, 1}$ & 0.345 \\
\hline $\mathrm{k}_{\mathrm{i}, 2}$ & 0.139 \\
\hline $\mathrm{k}_{\mathrm{i}, 3}$ & 0.014 \\
\hline
\end{tabular}

...where $t$ (min) was the contact time, $Q_{e}(\mathrm{mg} / \mathrm{g})$ and $\mathrm{Q}_{\mathrm{t}}(\mathrm{mg} / \mathrm{g})$ was the adsorption capacity of $\mathrm{Fe}_{3} \mathrm{O}_{4} / \mathrm{CTS}$ magnetic nanoparticles on Mo (VI) at adsorption equilibrium and at adsorption of $\mathrm{t}$ min, respectively. $\mathrm{C}$ was boundary layer constant. $\mathrm{k}_{1}$ and $\mathrm{k}_{2}$ was the velocity constants of pseudo-first-order and pseudosecond-order dynamics, respectively. $\mathrm{k}_{\mathrm{p}}$ was particle diffusion dynamics parameter. When the adsorption rate was proportional to the number of adsorption sites unoccupied by the adsorbent, the adsorption process conformed to pseudo-first-order kinetics. If the occupancy rate of the binding site was proportional to the square of the unoccupied site, adsorption conformed to pseudo-second-order kinetics [40].

For sodium molybdate solution with an initial concentration of $30 \mathrm{mg} / \mathrm{L}$, the adsorption rate of Mo (VI) was very fast within $30 \mathrm{~min}$ and reached adsorption equilibrium for about $60 \mathrm{~min}$. Per gram of $\mathrm{Fe}_{3} \mathrm{O}_{4} / \mathrm{CTS}$ magnetic nanoparticles were able to adsorb $7.4 \mathrm{mg}$ Mo (VI), and the concentration of Mo (VI) was $0.38 \mathrm{mg} / \mathrm{L}$ at this point. Adsorption kinetics of Mo (VI) were shown in Fig. 7 and the fitting results were shown in Table 1. From Fig. 7 and Table $1, \mathrm{Q}_{\mathrm{t}} / \mathrm{t}$ had a good linear relationship with $\mathrm{t}, \mathrm{R}^{2}=0.9999$, the saturated adsorption capacity was similar to the experimental results, and the pseudo-second-order kinetics could better fit the adsorption of $\mathrm{Mo}$ (VI) by $\mathrm{Fe}_{3} \mathrm{O}_{4} / \mathrm{CTS}$ magnetic nanoparticles. This suggested that the steps to control the adsorption rate might be limited by the chemical adsorption of shared or exchanged electrons between the adsorbent and adsorbate [14]. The driving force of this process depended on the square of the adsorption vacancy point [35], which could explain the a)
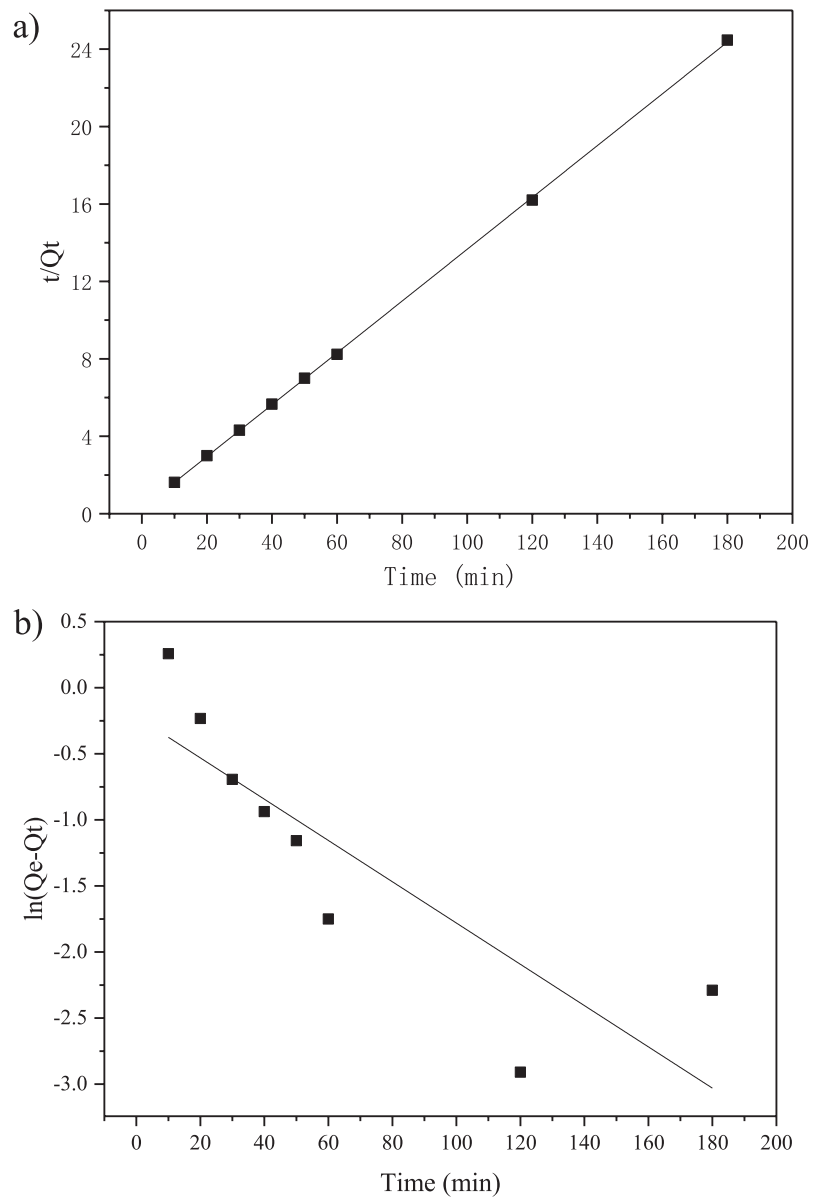

Fig. 7. Adsorption kinetics of Mo (VI). (a) pseudo-secondorder kinetic model and (b) pseudo-second-order kinetic model. Condition: $\mathrm{T}=298 \mathrm{~K}, \mathrm{pH}=4.0, \mathrm{Fe}_{3} \mathrm{O}_{4} / \mathrm{CTS}$ magnetic nanoparticles $0.40 \mathrm{~g}, 100 \mathrm{~mL}$ of $30 \mathrm{mg} / \mathrm{L} \mathrm{Mo}(\mathrm{VI})$.

fast adsorption rate in the early stage of adsorption, but in the later stage of adsorption, the decrease of adsorption vacancy points on $\mathrm{Fe}_{3} \mathrm{O}_{4} / \mathrm{CTS}$ magnetic nanoparticles and the decrease of chemical driving force brought by the decrease of Mo (VI) concentration led to slower adsorption rates [41].

Intramolecular diffusion model took $\mathrm{t}^{0.5}$ as the abscissa and adsorption capacity as the ordinate. The fitting results were shown in Fig. 8. The straight line in the diagram does not pass through the origin, indicating that the internal diffusion of particles is not the only step to control the adsorption rate. Therefore, the adsorption of $\mathrm{Mo}$ (VI) by $\mathrm{Fe}_{3} \mathrm{O}_{4} / \mathrm{CTS}$ magnetic nanoparticles may be divided into three stages. According to the fitting data of Table 1, with the increase of adsorption time, the adsorption rate becomes slower. The slope of the three-segment broken line was the diffusion rate constant of particle diffusion: $\mathrm{k}_{\mathrm{i}, 1}>\mathrm{k}_{\mathrm{i}, 2}>\mathrm{k}_{\mathrm{i}, 3}$. The adsorption process of Mo (VI) on $\mathrm{Fe}_{3} \mathrm{O}_{4} / \mathrm{CTS}$ magnetic nanoparticles may be that in the first stage of adsorption Mo (VI) bind to the adsorbable active sites of functional groups on the surface of $\mathrm{Fe}_{3} \mathrm{O}_{4} / \mathrm{CTS}$ magnetic nanoparticles, and the initial 


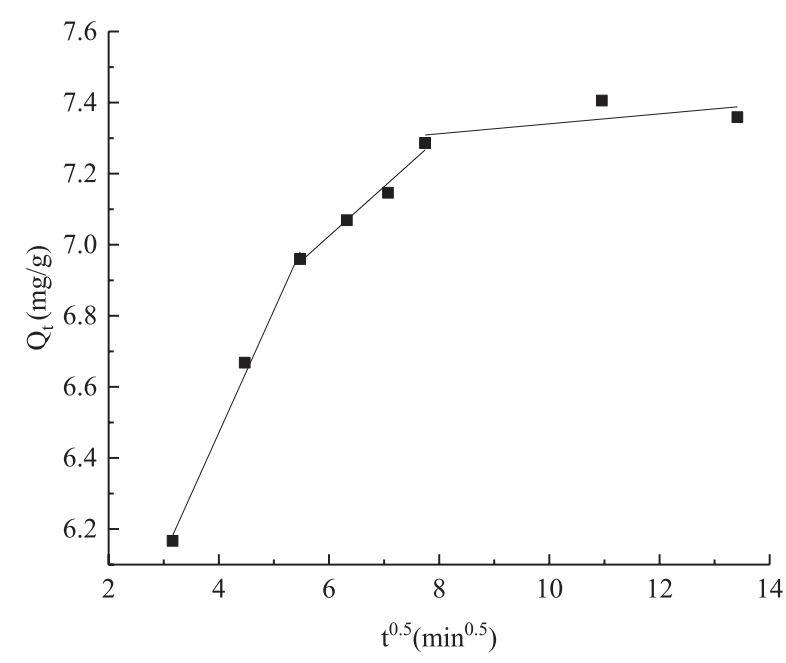

Fig. 8. Intra particle diffusion model of Mo (VI) absorbed on $\mathrm{Fe}_{3} \mathrm{O}_{4} /$ CTS magnetic nanoparticles. Condition: $\mathrm{T}=298 \mathrm{~K}$, $\mathrm{pH}=4, \mathrm{Fe}_{3} \mathrm{O}_{4} / \mathrm{CTS}$ magnetic nanoparticles $0.40 \mathrm{~g}, 100 \mathrm{~mL}$ of $30 \mathrm{mg} / \mathrm{L} \mathrm{Mo}$ (VI).

adsorption rate was fast. When the number of active sites on the surface decreases gradually, it began to enter the second stage of adsorption. The adsorption sites on the surface of $\mathrm{Fe}_{3} \mathrm{O}_{4}$ /CTS magnetic nanoparticles were basically occupied by Mo (VI). While Mo (VI) began to enter the micropores of the magnetic nanoparticles and were adsorbed by the pores. At the third stage of adsorption, the adsorption sites on the surface of $\mathrm{Fe}_{3} \mathrm{O}_{4} / \mathrm{CTS}$ magnetic nanoparticles and in the pore basically saturated. The adsorption reached equilibrium state at this time. Through the model of particle diffusion, it could be concluded that the adsorption of $\mathrm{Mo}$ (VI) on $\mathrm{Fe}_{3} \mathrm{O}_{4} / \mathrm{CTS}$ magnetic nanoparticles is not only chemical chelation, but also internal diffusion.

\section{Adsorption Isotherms}

Adsorption isotherms studied the relationship between adsorption capacity and Mo (VI) concentration of $\mathrm{Fe}_{3} \mathrm{O}_{4} / \mathrm{CTS}$ magnetic nanoparticles at constant temperature. The experiments were carried out at room temperature. The concentration in the range of 30 $210 \mathrm{mg} / \mathrm{L}$ was selected as the initial concentration of Mo (VI) using Langmuir model [42] and Freundlich model [43] fitting of adsorption process. Equations were expressed as (5)-(6):

$$
\begin{gathered}
\frac{C_{e}}{Q_{e}}=\frac{C_{e}}{Q_{m}}+\frac{1}{K_{L} Q_{m}} \\
\ln Q_{e}=\ln K_{F}+\frac{1}{n} \ln C_{e}
\end{gathered}
$$

...where $\mathrm{Q}_{\mathrm{m}}(\mathrm{mg} / \mathrm{g})$ was the largest monolayer adsorption capacity, $Q_{e}(\mathrm{mg} / \mathrm{g})$ indicated adsorption capacity
Table 2. Parameters of Langmuir and Freundlich isotherm equations for the adsorption of Mo (VI) at $298 \mathrm{~K}$.

\begin{tabular}{|c|c|}
\hline Adsorption model & Mo(VI) ion \\
\hline \multicolumn{2}{|c|}{ Langmuir isotherm } \\
\hline $\mathrm{Q}_{\mathrm{m}}(\mathrm{mg} / \mathrm{g})$ & 35.54 \\
\hline $\mathrm{K}_{\mathrm{L}}(\mathrm{L} / \mathrm{mg})$ & 0.08 \\
\hline $\mathrm{R}^{2}$ & 0.9978 \\
\hline \multicolumn{2}{|c|}{ Freundlich isotherm } \\
\hline $\mathrm{n}$ & 2.36 \\
\hline $\mathrm{K}_{\mathrm{F}}\left(\mathrm{mg}^{1-1 / \mathrm{n}} \mathrm{L}^{1 / \mathrm{n}} / \mathrm{g}\right)$ & 5.42 \\
\hline $\mathrm{R}^{2}$ & 0.9501 \\
\hline
\end{tabular}

at adsorption equilibrium, $\mathrm{C}_{\mathrm{e}}(\mathrm{mg} / \mathrm{L})$ indicated the concentration of Mo (VI) in adsorption equilibrium, $\mathrm{K}_{\mathrm{L}}$ and $\mathrm{K}_{\mathrm{F}}$ was Langmuir and Freundlich constants, respectively, $1 / \mathrm{n}$ was the adsorption index.

Table 2 showed the fitting results. The results showed that although the adsorption equilibrium concentration $\mathrm{C}_{e}$ of Mo (VI) increased with the increase of initial concentration, the equilibrium adsorption capacity of the adsorbed material $\mathrm{Q}_{\mathrm{e}}$ was also increasing. Using linear regression to process the isotherm data, Fig. 9a) and 9b) indicated the linear relation of $\mathrm{C}_{\mathrm{e}} / \mathrm{Q}_{\mathrm{e}}$ to $\mathrm{C}_{\mathrm{e}}$ and $\ln \mathrm{Q}_{\mathrm{e}}$ to $\operatorname{lnC} \mathrm{e}_{\mathrm{e}}$. In Fig. 9a), $\mathrm{Q}_{\mathrm{m}}$ and $\mathrm{K}_{\mathrm{L}}$ could be calculated and the correlation coefficient $\mathrm{R}^{2}=0.99777$ was closer to 1 than that of Freundlich model. Freundlich model was more suitable for adsorption on highly hybrid surfaces lacking saturated adsorption platforms [43], while Langmuir model was more suitable for adsorption of Mo (VI) by $\mathrm{Fe}_{3} \mathrm{O}_{4} / \mathrm{CTS}$ magnetic nanoparticles at room temperature. The average saturated adsorption capacity of $31.46 \mathrm{mg} / \mathrm{g}$ was very close to the calculated maximum adsorption capacity $\mathrm{Q}_{\mathrm{m}}=35.54 \mathrm{mg} / \mathrm{g}$. Langmuir model assumed that the adsorption effect was monolayer, so $\mathrm{Fe}_{3} \mathrm{O}_{4} / \mathrm{CTS}$ magnetic nanoparticles were monolayer adsorption. Each active site could only adsorb one molecule, and all the adsorption sites were in the same priority, forming a uniform monolayer adsorption membrane [29]. Table 3 compared the $\mathrm{Fe}_{3} \mathrm{O}_{4} / \mathrm{CTS}$ magnetic nanoparticles with other adsorbed materials in the removal of Mo (VI). Obviously, the removal performance of $\mathrm{Fe}_{3} \mathrm{O}_{4} / \mathrm{CTS}$ magnetic nanoparticles to $\mathrm{Mo}$ (VI) was good, the adsorption capacity was $35.54 \mathrm{mg} / \mathrm{g}$, which was better than that of D2EHPA-functionalized magnetite $(25.8 \mathrm{mg} / \mathrm{g})$ [44], zeolite-supported magnetite (18.02 $\mathrm{mg} / \mathrm{g})$ [45], sulfuric acid-modified cinder (31.08 mg/g) [46]. Even though there were adsorbents like polysiloxane modified with DETAP $(111.84 \mathrm{mg} / \mathrm{g})$ [47] and QA-MNP (65 mg/g) [35] with excellent adsorption properties, the preparation of these adsorbents might be complex and costly, which was not conducive to production and application. 

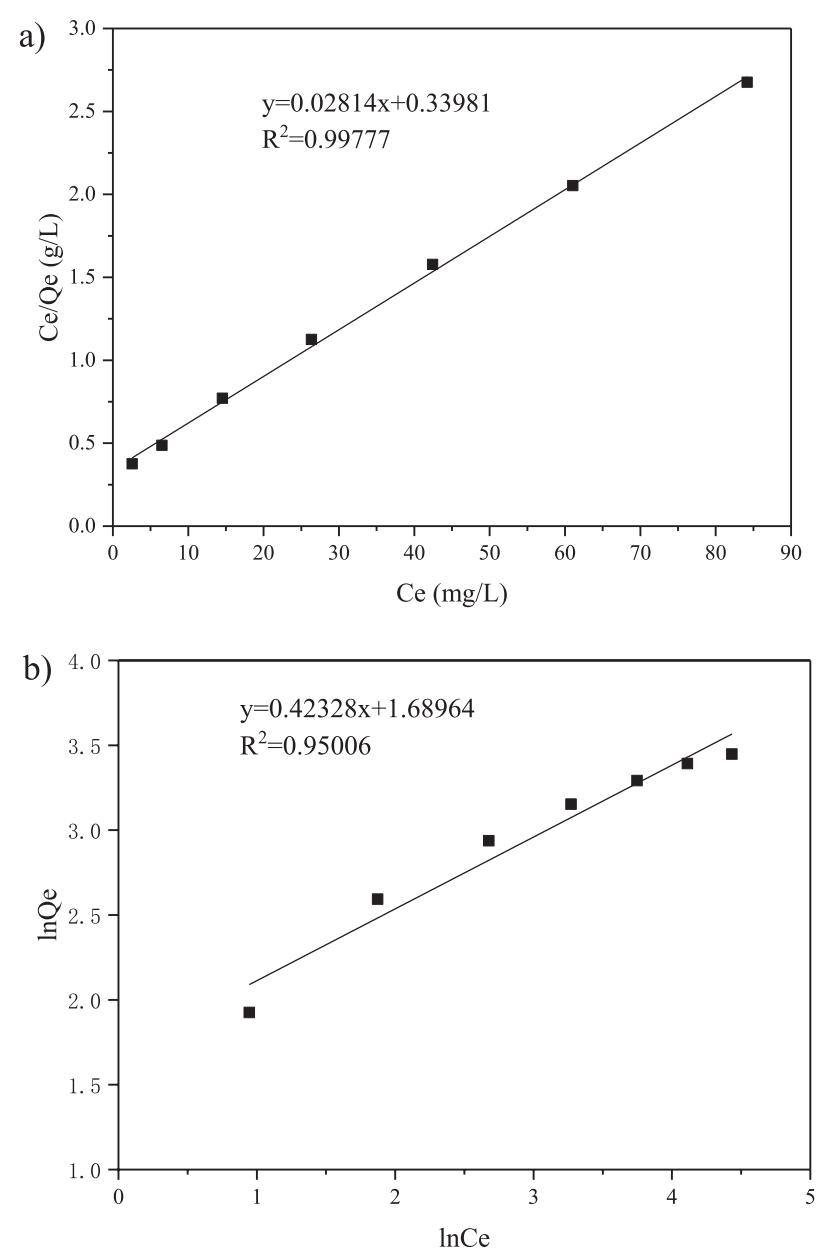

Fig. 9. Adsorption isotherms of Mo (VI). a) Langmuir model and b) Freundlich model. Condition: $\mathrm{T}=298 \mathrm{~K}, \mathrm{pH}=4$, nano-magnetic $\mathrm{Fe}_{3} \mathrm{O}_{4} / \mathrm{CTS} 0.40 \mathrm{~g}$, Mo initial concentration $30-210 \mathrm{mg} / \mathrm{L}$, solution volume $100 \mathrm{~mL}$.

\section{Desorption and Regeneration Test}

The reusability of adsorbed materials was an important factor for measuring its efficiency. In order to make the adsorption process of Mo (VI) by $\mathrm{Fe}_{3} \mathrm{O}_{4} / \mathrm{CTS}$ magnetic nanoparticles more economical and effective, the desorption experiment of this adsorption material was studied. Using $0.01 \mathrm{~mol} / \mathrm{L} \mathrm{NaOH}$ solution for ultrasonic treatment of adsorbed equilibrium water

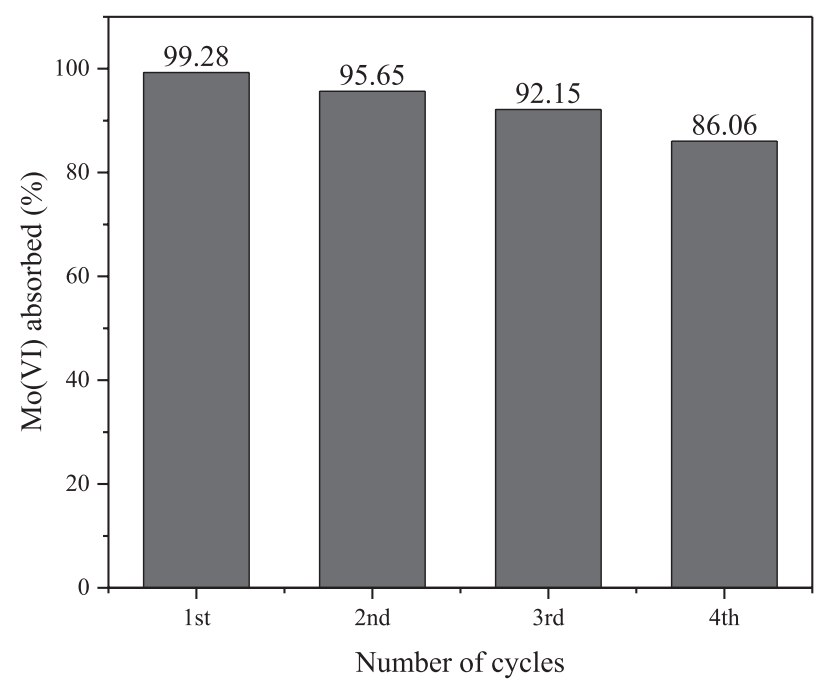

Fig. 10. Performance of $\mathrm{Fe}_{3} \mathrm{O}_{4} / \mathrm{CTS}$ magnetic nanoparticles by multiple cycles of regeneration. Desorption condition: $0.01 \mathrm{~N}$ $\mathrm{NaOH}$ solutions for $30 \mathrm{~min}$ at $298 \mathrm{~K}$.

samples, the magnetic separation of solid solution was used to obtain the regenerated composite nanomaterials, and the relationship between the regeneration times of $\mathrm{Fe}_{3} \mathrm{O}_{4} / \mathrm{CTS}$ magnetic nanoparticles and the removal rate of Mo (VI) were studied. The performance of $\mathrm{Fe}_{3} \mathrm{O}_{4} / \mathrm{CTS}$ magnetic nanoparticles by multiple cycles of regeneration were shown in Fig. 10. The results showed that the removal rate of Mo (VI) was $99.28 \%$ at adsorption equilibrium, and the adsorption capacity decreased gradually with the increase of regeneration times. The removal rate of Mo (VI) after one regeneration of $\mathrm{Fe}_{3} \mathrm{O}_{4} / \mathrm{CTS}$ magnetic nanoparticles was $95.65 \%$, and the removal rate decreased to $92.15 \%$ after two regenerations, which still reached more than $90 \%$. According to the similar consistency principle and electrostatic repulsion [13], $\mathrm{OH}^{-}$on $\mathrm{NaOH}$ solution could replace Mo (VI) at the adsorption site of $\mathrm{Fe}_{3} \mathrm{O}_{4} / \mathrm{CTS}$ particle, which enabled the regenerated adsorbate material to be reused and obtain the ability to adsorb Mo (VI) again [48]. However, the reason for the decrease of adsorption capacity might be that there was still a small amount of Mo (VI) on the regenerated $\mathrm{Fe}_{3} \mathrm{O}_{4} /$ CTS magnetic nanoparticles, leading to the

Table 3. Comparison between adsorption of Mo (VI) by $\mathrm{Fe}_{3} \mathrm{O}_{4} / \mathrm{CTS}$ magnetic nanoparticles and other adsorbents.

\begin{tabular}{|c|c|c|}
\hline Adsorbents & Adsorption capacity (mg/g) & References \\
\hline Polysiloxane modified with DETAP & 111.84 & Sharma et al. (2012) \\
\hline Zeolite-supported magnetite & 18.02 & Verbinnen et al. (2013) \\
\hline D2EHPA- functionalized magnetite & 25.8 & Hassanpour et al. (2016) \\
\hline $\mathrm{Fe}_{3} \mathrm{O}_{4} @ \mathrm{SiO}_{2}$ & 31.08 & Gaete et al. (2019) \\
\hline QA-MNP & 65 & This study \\
\hline $\mathrm{Fe}_{3} \mathrm{O}_{4} / \mathrm{CTS}$ magnetic nanoparticles & 35.54 & \\
\hline
\end{tabular}


decrease of adsorption vacancy as well as to a removal rate that was lower than the initial adsorption rate [29, 41].

\section{Conclusions}

$\mathrm{Fe}_{3} \mathrm{O}_{4} / \mathrm{CTS}$ magnetic nanoparticles were synthesized by reverse suspension cross-linking. The chitosanmodified magnetic nanoparticles were completely consistent with the diffraction peaks of $\mathrm{Fe}_{3} \mathrm{O}_{4}$ magnetic nanoparticles, indicating that the phase transition of $\mathrm{Fe}_{3} \mathrm{O}_{4}$ nanoparticles was not caused during the binding of chitosan, and the crystal structure did not change. FTIR spectra showed that $\mathrm{Fe}_{3} \mathrm{O}_{4} / \mathrm{CTS}$ magnetic nanoparticles were formed successfully after the chemical effect of $\mathrm{Fe}_{3} \mathrm{O}_{4}$ on chitosan. Zero potential point $\left(\mathrm{pH}_{\mathrm{pzc}}\right)$ of nanocomposites was observed near $\mathrm{pH}=5.3$. The results showed that the removal effect of molybdenum was the best under the condition of $\mathrm{pH}=4.0$, and the removal rate is $94.35 \%$. The adsorption behavior of $\mathrm{Mo}(\mathrm{VI})$ on $\mathrm{Fe}_{3} \mathrm{O}_{4} / \mathrm{CTS}$ magnetic nanoparticles followed the Langmuir isotherm, the maximum adsorption capacity was $35.54 \mathrm{mg} / \mathrm{g}$. Pseudosecond-order kinetics can accurately describe the adsorption process. At the same time, the adsorption process of molybdenum on $\mathrm{Fe}_{3} \mathrm{O}_{4} / \mathrm{CTS}$ magnetic nanoparticles had the effect of intraparticle diffusion. Through the experimental study of desorption and regeneration of nano-adsorbed materials, the removal rate of molybdenum could still reach $92.15 \%$ after two regeneration, indicating that $\mathrm{Fe}_{3} \mathrm{O}_{4} / \mathrm{CTS}$ magnetic nanoparticles had a good reproducibility, strong reusability and good removal effect of Mo (VI). The $\mathrm{Fe}_{3} \mathrm{O}_{4} /$ CTS magnetic nanoparticles were a kind of good adsorption material with great prospects for rapid and efficient adsorption, which could be reused and had a broad research prospect.

\section{Acknowledgements}

This research was funded by the China National Critical Project for Science and Technology on Water Pollution Prevention and Control (No. 2018ZX07601002).

\section{Conflict of Interest}

The authors declare no conflict of interest.

\section{References}

1. TSAI K.S., CHANG Y.M., KAO J.C., LIN K.L. Groundwater molybdenum from emerging industries in Taiwan. Bull Environ Contam Toxicol, 96 (1), 102, 2016.
2. FRASCOLI F., HUDSON-EDWARDS K.A. Geochemistry, Mineralogy and Microbiology of Molybdenum in MiningAffected Environments. Minerals, 8 (2), 42, 2018.

3. BATTOGTOKH B., LEE J. M., WOO N. Contamination of water and soil by the Erdenet copper-molybdenum mine in Mongolia. Environ Earth Sci, 71 (8), 3363, 2014.

4. HALMI M.I., WASOH H., SUKOR S., AHMAD S.A., YUSOF M.T., SHUKOR M.Y. Bioremoval of molybdenum from aqueous solution. Int J Agric Biol, 16 (4), 848, 2014.

5. TIMOFEEV I., KOSHELEVA N., KASIMOV N. Contamination of soils by potentially toxic elements in the impact zone of tungsten molybdenum ore mine in the Baikal region: A survey and risk assessment. Sci Total Environ, 642, 63, 2018.

6. QIN J., CUI X., YAN H., LU W., LIN C. Active treatment of acidic mine water to minimize environmental impacts in a densely populated downstream area. J Clean Prod, 210, 309, 2019.

7. NAMASIVAYAM C., SANGEETHA D. Removal of molybdate from water by adsorption onto $\mathrm{ZnCl}_{2}$ activated coir pith carbon. Biores Tech, 97 (10), 1194, 2006.

8. LIAN J., HUANG Y., CHEN B., WANG S., WANG P., NIU S., LIU Z. Removal of molybdenum(VI) from aqueous solutions using nano zero-valent iron supported on biochar enhanced by cetyl-trimethyl ammonium bromide: adsorption kinetic, isotherm and mechanism studies. Wat. Sci. Tech, 3, 859, 2017.

9. MAMTAZ R., BACHE D.H. Reduction of arsenic in groundwater by coprecipitation with iron. J. Water. Supply. Res. T, 50 (5), 313, 2001.

10. POLOWCZYL I., CYGANOWSKI P., URBANO B.F., RIVAS B.L., BRYJAK M., KABAY N. Amberlite IRA-400 and IRA-743 chelating resins for the sorption and recovery of molybdenum (VI) and vanadium (V): equilibrium and kinetic studies. Hydrometallurgy, 169, 496, 2017.

11. SHAN W.J., SHU Y.N., CHEN H., ZHANG D.Y., WANG W., RU H.Q., XIONG Y. The recovery of molybdenum (VI) from rhenium (VII) on amino-functionalized mesoporous materials. Hydrometallurgy, 165, 251, 2016.

12. NAMASIVAYAM C., SURESHKUMAR V.M. Removal and recovery of molybdenumfrom aqueous solutions by adsorption onto surfactant-modified coir pith, alignocellulosic polymer. Clean-Soil Air Water, 37 (1), 60, 2009.

13. LOU Z.N., WANG J., JIN X.D., WAN L., WANG Y., CHEN H., SHAN W.J., XIONG Y. Brown algae based new sorption material for fractional recovery of molybdenum and rhenium from wastewater. Chem Eng J, 273, 231, 2015.

14. LIAN J., ZHOU F., CHEN B., YANG M., WANG S., LIU Z, NIU S. Enhanced adsorption of molybdenum (VI) onto drinking water treatment residues modified by thermal treatment and acid activation. J Cleaner Prod, 244, 118719, 2020.

15. ALLAEDINI G., TASIRIN S. M., AMINAYI P. Synthesis of $\mathrm{Fe}-\mathrm{Ni}-\mathrm{Ce}$ trimetallic catalyst nanoparticles via impregnation and co-precipitation and their application to dye degradation. Chem Pap, 70 (2), 231, 2016.

16. SINGH R., KUMAR K., KHAJURIA H., LADOL J., SHEIKH H.N. Hydrothermal synthesis of magnetic $\mathrm{Fe}_{3} \mathrm{O}_{4}$-nitrogen-doped graphene hybrid composite and its application as photocatalyst in degradation of methyl orange and methylene blue dyes in presence of copper (II) ions. Chem Pap, 72 (1), 1, 2018.

17. BANERJEE S., DUBEY S., GAUTAM R.K., CHATTOPADHYAYA M.C., SHARMA Y.C. Adsorption characteristics of alumina nanoparticles for the removal of 
hazardous dye, Orange $\mathrm{G}$ from aqueous solutions. Arab J Chem, 12 (8), 5339, 2019.

18. HAQ S., REHMAN W., WASEEM M. Adsorption Efficiency of Anatase $\mathrm{TiO}_{2}$ Nanoparticles Against Cadmium Ions. J Inorg Polym Mater, 29 (3), 651, 2019.

19. UDDIN M.K., BAIG U. Synthesis of $\mathrm{Co}_{3} \mathrm{O}_{4}$ nanoparticles and their performance towards methyl orange dye removal: Characterisation, adsorption and response surface methodology. J Clean Prod, 211, 1141, 2019.

20. LI K., LI P., CAI J., XIAO S., YANG H., LI A. Efficient adsorption of both methyl orange and chromium from their aqueous mixtures using a quaternary ammonium salt modified chitosan magnetic composite adsorbent. Chemosphere, 154, 310, 2016.

21. BUDNYAK T.M., TERTYKH V.A., YANOVSKA E.S., KOŁODYŃSKA D., BARTYZEL A. Adsorption of $\mathrm{V}$ (V), Mo (VI) and Cr (VI) oxoanions by chitosan-silica composite synthesized by Mannich reaction. Ads Sci Tech, 33, 645, 2015.

22. BRION-ROBY R., GAGNON J., NOSRATI S., DESCHÊNESB J.S., CHABOTD B. Adsorption and desorption of molybdenum (VI) in contaminated water using a chitosan sorbent. J Water Process Eng, 23, 13, 2018.

23. BERTONI F.A., GONZÁLEZ J. C., GARCÍA S.I., SALA L.F., BELL'U S.E. Application of chitosan in removal of molybdate ions from contaminated water and groundwater. Carbohydr Polym, 180, 55, 2018.

24. DAHAGHIN Z., MOUSAVI H.Z., MIRPARIZI E., HAGHIGHAT P. Synthesis and application of a novel magnetic nanosorbent for determination of trace Cd (II), $\mathrm{Ni}(\mathrm{II}), \mathrm{Pb}(\mathrm{II})$, and $\mathrm{Zn}(\mathrm{II})$ in environmental samples. Chem Pap, 72 (3-4), 1, 2018.

25. SINGARAJ S.G., MAHANTY B., BALACHANDRAN D., PADMAPRABHA A. Adsorption and desorption of chromium with humic acid coated iron oxide nanoparticles. Environ Sci Pollut Res, 26 (29), 30044, 2019.

26. ZHANG Y., NI S., WANG X., ZHANG W., LAGERQUIST L., QIN M., WILLFÖR S., XU X., FATEHI P. Ultrafast adsorption of heavy metal ions onto functionalized ligninbased hybrid magnetic nanoparticles. Chem Eng J, 372, 82, 2019.

27. GUO W., FU Z., ZHANG Z., WANG H., LIU S., FENG W., ZHAO X., GIESY J.P. Synthesis of $\mathrm{Fe}_{3} \mathrm{O}_{4}$ magnetic nanoparticles coated with cationic surfactants and their applications in $\mathrm{Sb}(\mathrm{V})$ removal from water. Sci Total Environ, 710, 136302, 2020.

28. LI G. Preparation of magnetic nano-chitosan microspheres and study of immobilized yeast cells. Central South University, 2008 [In Chinese].

29. AFKHAMI A., AGHAJANI S., MOHSENI M., MADRAKIAN T. Effectiveness of $\mathrm{Ni}_{05} \mathrm{Zn}_{05} \mathrm{Fe}_{2} \mathrm{O}_{4}$ for the removal and preconcentration of $\mathrm{Cr}(\mathrm{VI}), \mathrm{Mo}(\mathrm{VI}), \mathrm{V}(\mathrm{V})$ and $\mathrm{W}(\mathrm{VI})$ oxyanions from water and wastewater samples. J Iran Chem Soc, 12(11), 2007, 2015.

30. CROUTHAMEL C.E., JOHNSON C. E. Thiocyanate spectrophotometric determination of molybdenum and tungsten. Anal Chem, 26 (8), 1284, 1954.

31. AFKHAMI A., NOROOZ-ASL R. Removal, preconcentration and determination of Mo (VI) from water and wastewater samples using maghemite nanoparticles. Colloids Surf A, 346 (1), 52, 2009.

32. DING Y., SHEN S.Z., SUN H., SUN K., LIU F., QI Y., YAN J. Design and construction of polymerized-chitosan coated $\mathrm{Fe}_{3} \mathrm{O}_{4}$ magnetic nanoparticles and its application for hydrophobic drug delivery. Mater Sci Eng, 48, 487, 2015.

33. MI F.L., WU S.J., CHEN Y.C. Combination of carboxymethyl chitosan-coated magnetic nanoparticles and chitosan-citrate complex gel beads as a novel magnetic adsorbent. Carbohydr Polym, 131, 255, 2015.

34. HOSSEINI F., SADIGHIAN S., HOSSEINI-MONFARED H., MAHMOODI N.M. Dye removal and kinetics of adsorption by magnetic chitosan nanoparticles. Desalin Water Treat, 57 (51), 24378, 2016.

35. GAETE J., MOLINA L., ALFARO I. Recovery and separation of rhenium and molybdenum from aqueous solutions that simulate mine waters using magnetite nanoparticles functionalized with amine-derivative groups. Miner Eng, 136, 66, 2019.

36. GUIBAL E., MILOT C., TOBIN J.M. Metal-anion sorption by chitosan beads: equilibrium and kinetic studies. Ind Eng Chem Res, 37 (4), 1454, 1998.

37. HAMED M.M., RIZ H.E., AHMED I.M. Adsorption behavior of zirconium and molybdenum from nitric acid medium using low-cost adsorbent. J Mol Liq, 249, 361, 2018.

38. LAGERGREN S.K. About the theory of so-called adsorption of soluble substances. K Sven Vetensk Handl, 24, 1,1898

39. HO Y.S., MCKAY G. Pseudo-second order model for sorption processes. Process Biochem, 34 (5), 451, 1999.

40. KUMAR D., GAUR J.P. Chemical reaction-and particle diffusion-based kinetic modeling of metal biosorption by a Phormidium sp--dominated cyanobacterial mat. Bioresource Technol, 102 (2), 633, 2011.

41. TU Y.J., YOU C.F., CHANG C.K., CHAN T.S., LI S.H. XANES evidence of molybdenum adsorption onto novel fabricated nano-magnetic $\mathrm{CuFe}_{2} \mathrm{O}_{4}$. Chem Eng J, 244, 343, 2014.

42. LANGMUIR I. The adsorption of gases on plane surfaces of glass, mica and platinum. J Am Chem Soc, 40 (9), 1361, 1918.

43. FREUNDLICH H. Ueber die adsorption in Loesungen. Z Phys Chem, 57, 385, 1906.

44. AGARWAL S., TYAGI I., GUPTA V.K., HANIFPOUR F., MAGHSUDI M., JAVADIAN H. Mo (IV) adsorption from nitric acid media by Di-(2-ethylhexyl) phosphoric acid (D2EHPA) coated silanized magnetite nanoparticles. J Mol Liq, 218, 346, 2016.

45. VERBINNEN B., BLOCK C., LIEVENS P., BRECHT A.V., VANDECASTEELE C. Simultaneous removal of molybdenum, antimony and selenium oxyanions from wastewater by adsorption on supported magnetite. Waste Biomass Valoriz, 4 (3), 635, 2013.

46. HASSANPOUR S., TAGHIZADEH M. Rapid and selective separation of molybdenum ions using a novel magnetic Mo (VI) ion imprinted polymer: a study of the adsorption properties. Rsc Adv, 6 (102), 100248, 2016.

47. SHARMA R.K., PANDEY A.P., GULATI S., ADHOLEYA A. Silica modified with 2, 6-diacetylpyridinemonosalicyloylhydrazone: A novel and selective organicinorganic sorbent for separation of molybdenum ions in a newly designed reactor. Chem Eng J, 210, 490, 2012.

48. CHEN Y., ZHANG Z., CHEN D., CHEN Y., GU Q., LIU $\mathrm{H}$. Removal of coke powders in coking diesel distillate using recyclable chitosan-grafted $\mathrm{Fe}_{3} \mathrm{O}_{4}$ magnetic nanoparticles. Fuel, 238, 345, 2019. 